\title{
11-13 Yaş Erkek Taekwondo Sporcularının Somatotip Yapıları ve Performans Özellikleri Arasındaki İlişkinin İncelenmesi*
}

\author{
Cengiz ÖLMEZ ${ }^{1 \dagger}$, Vedat AYAN², Selami YÜKSEK ${ }^{3}$, Mehmet ÖZTAŞ ${ }^{4}$, Tamer CívíL ${ }^{5}$ \\ ${ }^{1}$ Trabzon Üniversitesi Spor Bilimleri Fakültesi, Trabzon, https://orcid.org/0000-0001-8584-6272 \\ ${ }^{2}$ Trabzon Üniversitesi Spor Bilimleri Fakültesi, Trabzon, https://orcid.org/0000-0003-1887-5334 \\ ${ }^{3}$ Trabzon Üniversitesi Spor Bilimleri Fakültesi, Trabzon, https://orcid.org/0000-0002-2162-8660 \\ ${ }^{4}$ Erzincan Üniversitesi Beden Eğitim ve Spor Yüksekokulu, Erzincan, https://orcid.org/0000-0003-4689-6490 \\ ${ }^{5}$ Trabzon Üniversitesi Spor Bilimleri Fakültesi, Trabzon, https://orcid.org/0000-0003-0104-0007
}

Orijinal Makale

Gönderi Tarihi: 02.03.2019

\section{Öz}

Kabul Tarihi: 09.05.2019

DOI: $10.30769 /$ usbd.534672

Online Yayın Tarihi: 30.06.2019

$\mathrm{Bu}$ araştırma, Trabzon ili Akçaabat ilçesinde taekwondo sporu ile ilgilenen 11-13 yaş grubu sporcuların antropometrik, somatotip ve motorik performans özelliklerinin incelenmesi amacıyla yapıldı. Bu amaçla, 19 erkek (yaş 12,16 $\pm 0,69$ yıl, boy

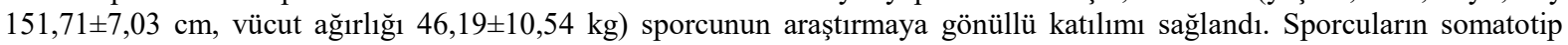
yapılarının tespit edilmesi amacıyla Heath-Carter yöntemi; motorik performansların tespit edilmesi amacıyla 20 metre sürat testi, Flamingo denge testi, dikey sıçrama testi, durarak uzun atlama testi, otur eriş esneklik testi, 30 saniye mekik testi, 30 saniye şınav testi, Illinois çeviklik testi ve Multistage Shuttle Run aerobik güç testi kullanıldı. Sporcuların anaerobik güçleri ise, Lewis nomogramı ile tespit edildi. Araştırmadan elde edilen verilerin istatistiksel analizi için SPSS 25.0 istatistik programı kullanıldı ve anlamlılık düzeyi olarak $\mathrm{p}<0,05$ değeri alındı. Sporcuların motorik performans seviyeleri ile somatotip yapıları arasındaki ilişkilerin tespit edilebilmesi için Spearman korelasyon katsayısı kullanıldı. Araştırmadan elde edilen bulgular; sporcuların endomorfik- mezomorf (4-5-3) bir yapıda olduğunu ve somatotip yapıları ile motorik performans seviyeleri arasında anlamlı ilişkiler olduğunu gösterdi $(\mathrm{p}<0,05)$. Sonuç olarak, sporcuların vücut kompozisyonu ve somatotip yapıları, onların sportif performanslarını etkileyebilmektedir. Bu çalışmadan elde edilen sonuçların sporda yetenek seçimi ve yönlendirme alanındaki mevcut literatüre ve ilgili spor insanlarına katkıda bulunacağı kanaatindeyiz. Anahtar kelimeler: Taekwondo, Performans, Somatotip

\section{The Investigation of Correlation Between Somatotype Structures and Performance Characteristics of 11-13 Ages Boy Taekwondo Athletes}

\begin{abstract}
This study was conducted to examine the anthropometric, somatotype and motoric performance characteristics of 11-13 ages athletes who take interest in taekwondo in Akçaabat village of Trabzon. For this purpose, 19 boys (age 12.16 \pm 0.69 years, height $151.71 \pm 7.03 \mathrm{~cm}$, body weight $46.19 \pm 10.54 \mathrm{~kg}$ ) athletes participated in this study voluntarily. Heath-Carter method was used to determine the somatotype characteristics performance of the athletes, and 20-meter speed test, Flamingo balance test, vertical jump test, standing long jump test, sit and reach test, 30 second sit-up test, 30 second push-up test, Illinois agility test and Multistage Shuttle Run aerobic power test were used to determine the motoric performance of the athletes. Lewis nomogram was also used to determine anaerobic power of the athletes. SPSS 25.0 statistical software was used for statistical analysis of the data obtained in the study and the threshold for significance level was $\mathrm{p}<0.05$. Spearman correlation coefficient was used to determine the correlations between motoric performance levels and somatotype structures of the athletes. The findings of the research demonstrate that the athletes have an endomorphic- mesomorph (4-5-3) structure and there were statistically significant relationships between somatotype structures and motoric performance levels of the athletes $(\mathrm{p}<0.05)$. As a result, body composition and somatotype structures of the athletes affect sportive performance of them. We are of opinion that the findings obtained through this study will contribute to the available literature in the field of talent selection and direction on sport and sports people.
\end{abstract}

Keywords: Taekwondo, Performance, Somatotype

\footnotetext{
* Bu çalışma, 05-08/ 07/ 2018 tarihinde Ürgüp/ Nevşehir'de düzenlenen II. International Scientific and Vocational Studies Congress'de sözel bildiri olarak sunulmuştur.

† Sorumlu Yazar: Cengiz ÖLMEZ, cengizolmez@ hotmail.com.tr
} 


\section{GíRiş}

Taekwondo; mental, ritmik ve teknik becerilerin yanı sıra kuvvet, sürat, dayanıklılık, çeviklik ve hareketlilik gibi özelliklerin üst düzeyde talep edildiği olimpik bir spordur (Marković ark., 2005). Taekwondo, Ülkemizde ve Dünyada oldukça yaygın ve sevilen bir spor dalıdır (Tel, 2008). Özellikle çocuklar için taekwondo; koordinatif becerilere, gelişime ve sağlık ile ilgili problemlerle baş etmeye olan katkıları bakımından oldukça ideal ve tercih edilebilir niteliktedir (Kim ve Khil, 2010).

Taekwondo; tüm spor dallarında olduğu gibi eğlence, sağlık, popülarite, saygınlık, iyi görünmek, iyi hissetmek ve maddi-manevi şampiyonluk avantajlarından faydalanmak gibi çeşitli amaçlar için bir araç olarak tercih edilebilir. Konu şampiyonluk olduğunda ise; bilimsel metotlarla yapılan yetenek seçimi, seçilen yeteneğin doğru antrene edilmesi ve performans değerlendirmesinin sporcuya özel olarak yapılması gibi bilim ve tecrübenin sahaya yansıtılması gerektiği konular öne çıkmakta ve sporda başarının kilit rolünü oluşturmaktadır (Marangoz, 2018).

Sporda performans kavramı, birçok değişkenin bir araya gelerek organize bir şekilde çalışmasını gerekli kılmaktadır. Performans, öncelikle icra edileceği uygun ortama ihtiyaç duyar. Sporcu, taekwondoya uygun zihinsel ve fiziksel yapıya sahip değilse, harcanan tüm emek ve çabaya rağmen istenilen amaca ulaşılamayabilir. Dolayısıyla kişinin ilgilenmekte olduğu spor dalına uygun özellikleri taşıyabilmesi ya da kendi özelliklerine uygun spor dalı ile ilgilenmesi, maksimum performansın sergilenebilmesi adına uygun bir yaklaşım olabilir. $\mathrm{Bu}$ anlamda, mevcut spor dallarının talep ettikleri fiziksel ve fizyolojik özelliklerin, her yaş ve kategori için bilimsel metotların kullanılarak, ayrıntılarla analiz edilmesi gerekmektedir (Kaynar, 2018).

Vücut yapısı, hareketlerin biyomekaniğini ve dolayısıyla performansını doğrudan etkilemektedir (Massidda ark., 2013). Fiziksel özelliklerin sportif performansı etkilediği düşüncesi çok sayıda araştırmanın konusu olmuştur ve her branş, yaş ve cinsiyet için incelenmeye değer görülmüştür. Örneğin yapılan çalışmalar, elit voleybolcuların, elit basketbol ve hentbolculardan daha uzun boylu, daha az yağ oranında ve dengeli mezomorf bir yapıya sahip olduklarını göstermiştir (Bayios ark., 2006). Katic ark., (2005) elit karate sporcularının mezomorfik bir yapıda olması gerektiğini rapor etmiştir. Sterkowicz ark., (2011), elit güreşçilerin mezomorf değerlerinin baskın olduğunu bildirmişlerdir. Massidda ark., (2013), yaptıkları araştırmada, erkek ve kadın cimnastik sporcularının somatotip yapılarının ektomorfik mezomorf olduğunu rapor etmişlerdir. Elit sporcuların ilgilendikleri spor dalında başarılı oldukları göz önünde bulundurulursa, spor dalının gerektirdiği özelliklere sahip oldukları yorumu yapılabilir. Böylece; ilgili spor dalına ait fiziksel, fizyolojik ve performans özelliklerinin ne olduğunu kestirebilmek adına elit sporcu profilleri incelenebilir. $\mathrm{Bu}$ sebeple, spor dallarının her yaş, cinsiyet ve kategoriye göre somatotip özellikleri ile motorik özellik talepleri arasındaki ilişkiler net olarak ortaya koyulmalı, incelenmeli ve rapor edilmelidir. Bu sayede spor dalının gerektirdiği özelliklere uygun performans ve fiziksel özellik normları oluşturulabilir, doğru antrenman programları hazırlanabilir ve fiziksel özelliklerden kaynaklı sportif performans problemleri için pratik çözümler geliştirilebilir. 
Çalışma, Ülkemizde ve Dünyada büyük kitleler halinde yapılan taekwondonun hem fiziksel uygunluğa hem de yetenek seçimi alanı için her yaşa ve cinsiyete göre sportif performans normlarının oluşturulmasına katkıları bakımından önemli bir kaynak olacaktır. Çocuklarda vücut tipi ve taekwondonun talep ettiği sportif performans özellikleri arasındaki ilişkinin ortaya koyulması, sporcu ve antrenörlerin kısa ve uzun vadede gerçekçi hedefler çizebilmelerine imkân tanıyacak, ilgili yaş grubu ve kategori için spesifik normların oluşmasına katkı sağlayacaktır. Dolayısıyla bu çalışma, 11-13 yaş grubu erkek taekwondocuların antropometrik, somatotip ve motorik performans özelliklerinin ve aralarındaki ilişkilerin incelenmesi amacıyla yapıldı.

\section{YÖNTEM}

\section{Çalışma grubu}

Çalışma, Trabzon İli Akçaabat İlçesinde taekwondo sporu ile ilgilenen 19 erkek sporcunun gönüllü katılımı, velilerinin yazılı izin onayları ve Helsinki Deklarasyonu prensiplerine uygun olarak gerçekleştirildi (World Medical Association, 2019). Sporcuların fiziksel ve demografik özelliklerine ait bilgiler, sporcu karteksine kayıt edildi.

\section{Veri Toplama}

Çalışmaya ait tüm ölçümler, Karadeniz Teknik Üniversitesi Beden Eğitimi ve Spor Yüksekokulu Fiziksel Performans Laboratuvarında, herhangi bir yarışmanın olmadığı hazırlık döneminde yapıldı.

\section{Antropometri ve Somatotip Ölçümleri}

Sporcuların boy uzunlukları; düz bir zemin ve duvardan faydalanılarak çelik metre, vücut ağırlıkları ise; üzerlerinde ağırlık yapmayacak giysi ile 0.1 kilogram hassasiyetli elektronik baskül (Tefal-5241) kullanılarak ölçüldü.

Vücut Kitle İndeksleri (VKİ); vücut ağırlığının kilogram cinsinden, boy uzunluğunun m cinsinden karesine bölünmesi yöntemiyle hesaplandı (James ark., 2005).

Vücut Yağ Yüzdeleri; skinfold kaliper ile calf ve subscapula bölgesinden alınan deri kıvrım kalınlığ1 ölçümleri ile önce vücut yoğunluğu (Vücut Yoğunluğu $=1.1043-0.00133 *$ (calf)$0.00131 *$ (subscapula) sonra da vücut yağ yüzdesinin (VYY= (4.57/Vücut Yoğunluğu)-4.142) $x$ 100) tespit edilmesi yöntemi ile hesaplandı (Kent and Kent, 2006).

Sporcuların endomorf, mezomorf ve ektomorf değerlerine ait somatotip özelliklerini belirlemek amacıyla Heath-Carter yöntemi kullanıldı. Deri kıvrımı ölçümleri için Holtain marka skinfold kaliper, çevre ölçüleri için esnek olmayan mezura ve çap ölçümler için Holtain marka kılavuzlu kumpas kullanıldı. Antropometrik ölçümler vücudun sağından ve aynı kişi tarafından alındı (Norton ve Olds, 2004).

\section{Motorik Testler}

Tüm sporculara motorik test ölçümlerine başlamadan önce 5-7 dk. jog düzeyinde koşu ve streching çalışmalarını içeren standart bir ısınma protokolü uygulandı. Sporcular, testler 
öncesi her test hakkında sözlü ve uygulamalı olarak bilgilendirildi. Sporculardan maksimum verim alınabilmesi için ölçümler esnasında motive edici dönütler verildi.

\section{0 m Sürat Testi}

Sporcuların sürat performanslarının tespiti için, çoklu sürat ölçümlerine olanak sağlayan Brove marka fotosel kullanılarak, $20 \mathrm{~m}$ sürat testi kullanıldı. Bu test, sporcunun anaerobik gücü, patlayıcı gücü, çabuk kuvveti ve ivmelenme yeteneği hakkında bilgi verir (Wood, 2017). Sporculardan, belirlenmiş olan $20 \mathrm{~m}$ uzunluğundaki düz bir koşu alanı üzerinde, verilecek olan uyarı komutu ile birlikte, maksimum kapasitelerini kullanarak koşmaları istendi. Test her sporcu için iki defa tekrar edildi ve en iyi sonuç sn. cinsinden kaydedildi. Denemeler arasında, fizyolojik süreçlerin tamamen yenilenebilmesine olanak sağlayan tam dinlenme ilkesine dikkat edildi.

\section{Illinois Çeviklik Testi}

Sporcuların çeviklik performanslarının tespit edilmesi amacıyla Illinois testi kullanıldı. Eni 5 $\mathrm{m}$, boyu $10 \mathrm{~m}$ ve orta bölümünde $3.3 \mathrm{~m}$ aralıklarla düz bir hat üzerine dizilmiş üç koniden oluşan bir test parkuru kuruldu. Test, her 10 m'de bir $180^{\circ}$ dönüşler içeren ve 40 m'si düz, 20 m'si ise koniler arasında gerçekleşen slalom koşusundan oluşmaktadır. Test öncesinde sporculara parkurun tanıtımı ve gerekli açıklamalar yapıldıktan sonra düşük tempoda 3-4 deneme yapmalarına izin verildi. Sporculardan test parkurunun başlangıç çizgisinde, yüzüstü yatar pozisyonda ve eller omuz hizasında yerle temas halindeyken çıkış yapmaları istendi. Tam dinlenme ilkesi ile test $2 \mathrm{kez}$ tekrarlandı ve en iyi değer sn. cinsinden kaydedildi (Reilly ve Williams, 2003).

\section{Dikey Sıçrama Testi}

Sporcunun sıçrama kuvvetinin tespit edilmesi amacıyla dikey sıçrama testi $\left(r_{x y}=0.97\right)$ kullanıldı (Aragón, 2000). Test öncesi, öğrencinin test yapılacak platform önünde, tek kolu ile uzanabildiği maksimum yükseklik belirlendi. Öğrencinin sabit noktada uzanabildiği nokta ile sıçrayarak uzanabildiği en yüksek nokta arasındaki fark belirlenip, yükseklik cm cinsinden kaydedildi (James ark., 2005). Tüm sporcular için test iki defa tekrar edildi ve en iyi sonuç kaydedildi.

\section{Anaerobik Güç Testi}

Dikey sıçrama testinden elde edilen sonuçlarla, Lewis formülü $\left(r_{x y}=0.83\right)$ kullanılarak sporcuların anaerobik güç değerleri hesaplandı ve sonuç watts ve $\mathrm{kgm} / \mathrm{sn}$. cinsinden kaydedildi (Fox ve Mathews, 1974). Sporcuların anaerobik güç değerleri; $P=[\sqrt{ } 4.9$ (vücut ağırliğl $\mathrm{kg}$ )] $x$ ل dikey siçrama mesafesi (m.) $\times 9.81$ (watts) ve $P=[\sqrt{ } 4.9$ (vücut ă̆grlı̆̆ $\mathrm{kg}$ ) $] x$ $\sqrt{ }$ dikey sıçrama mesafesi $(\mathrm{m}$.) $(\mathrm{kgm} / \mathrm{sn}$.) formülleri ile hesapland. 


\section{Flamingo Denge Testi}

Sporcuların denge kabiliyetlerini belirlemek amacıyla, yüksek güvenirlik katsayısına sahip $\left(\mathrm{r}_{\mathrm{xy}}=0.73\right)$ flamingo denge testi uygulandı (Tsigilis, Douda ve Tokmakidis, 2002). Test için, $50 \mathrm{~cm}$ uzunluğunda, $5 \mathrm{~cm}$ yüksekliğinde ve $3 \mathrm{~cm}$ genişliğinde düz ve esnek olmayan metal kiriş kullanıldı. $\mathrm{Bu}$ kiriş $15 \mathrm{~cm}$ uzunluğunda ve $4 \mathrm{~cm}$ genişliğinde iki ahşap destek ile sabitlendi. Her bir katılımcıdan, dengesini sağlamak amacıyla yardımcının elini tutup, baskın ayağı ile tek ayağı üzerinde durması ve boşta kalan diğer ayağını dizinden arkaya doğru bükerek, aynı yöndeki eli ile tutması istendi. Sporcu hazır olduğunda yardımcının elini bıraktı ve aynı anda kronometre çalıştırıldı. Sporcu her dengesini kaybedişinde (yerle temas etme, ayağını bırakma) kronometre durduruldu ve sporcu hazır olduğunda tekrar başlatıldı. 60 sn. süre içindeki toplam denge kaybetme sayısı kaydedildi (Wood, 2018). Test, sporcular tam dinlenik durumda iken uyguland1.

\section{Mekik Testi}

Sporcuların abdominal ve kalça-fleksör kaslarının dayanıklılığını tespit etmek amacıyla, yüksek güvenirlik katsayısına sahip $\left(\mathrm{r}_{\mathrm{xy}}=0.93\right) 30$ sn. mekik testi uygulandı (James et al., 2005). Her bir katılımcıdan, sırt üstü pozisyonda yatmaları ve ellerini ensede birbirine kenetlemesi istendi. Sporcunun ayak tabanlarının yerde olması ve dizlerinin $90^{\circ}$ bükülü olması sağlandıktan sonra, katılımcıdan $30 \mathrm{sn}$. boyunca mekik hareketi yapması istendi ve toplam yapılan mekik sayısı kaydedildi (Tamer, 2000). Test sirasında sporcular yere yattıklarında omuzları yere, kalkış pozisyonunda ise dirseklerinin dizlere değmesine dikkat edildi.

\section{Şınav Testi}

Sporcuların üst gövde kuvvet ve dayanıklılıklarını tespit etmek amacıyla yüksek güvenirlik katsayısına sahip $\left(r_{x y}=0.93\right) 30$ sn. süreli şınav testi uygulandı (James et al., 2005). Her bir katılımcıdan yere sabitlenmiş cimnastik minderi üzerinde yüzüstü pozisyonda yatması ve verilen "hazır" komutu ile ayak parmakları üzerinde, eller omuz genişliğinde açık ve kollar gergin bir şekilde pozisyon alması ve daha sonra verilen "başla" komutu ile $30 \mathrm{sn}$. boyunca yapabildiği kadar şınav hareketi yapması istendi. Yapılan maksimum şınav sayısı kaydedildi (Wood, 2018).

\section{Otur Eriş Esneklik Testi}

Sporcuların alt ekstremite ve hamstring kas esnekliklerini tespit etmek amacıyla, yüksek güvenirlik katsayısına sahip $\left(r_{x y}>0.90\right)$ olan otur eriş esneklik testi uygulandı (James et al., 2005). Katılımcıdan yerde, ayak parmak uçları yukarıda ve topuklar yere basacak bir pozisyonda oturması istendi. Sporcunun topuklarının yere temas ettiği iki nokta üzerinden düz bir hat çekildi ve sıfır noktası kabul edildi. Katılımcıdan dizlerinde bükülme olmaksızın uzanabildiği son noktaya kadar uzanması istendi (Wood, 2018). Her bir sporcu için test ikişer defa tekrar edildi ve en iyi sonuç (+) ya da (-) olarak cm cinsinden kaydedildi. 


\section{Durarak Uzun Atlama Testi}

Sporcuların denge ve koordinasyon ile birlikte dikey ve yatay eksende alt ekstremite güçlerini tespit etmek amaciyla durarak uzun atlama testi uygulandı. Sporcu düz bir zeminde ayak parmak uçları çizgi üzerinde, kollar geride, dizler hafif fleksiyonda ve gövde hafif öne eğilmiş bir pozisyonda iken ileriye doğru mümkün olan en uzak mesafeye sıçradı ve ayak topuğunun başlangıç çizgisine olan mesafesi ölçüldü. Test her sporcu için iki defa tekrar edildi ve en iyi sonuç sporcunun performans değeri olarak $\mathrm{cm}$ cinsinden kaydedildi (Maulder ve Cronin, 2005).

\section{Multistage Shuttle Run Aerobik Güç Testi}

Sporcuların aerobik güçlerinin tespit edilmesi amacıyla yüksek güvenirlik katsayısına sahip $\left(r_{x y}=0.77\right)$ multistage shuttle run aerobik güç testi uygulandı (Dardouri et al., 2014). Koşu alanı için $20 \mathrm{~m}$ uzunluğunda düz bir zemin kullanıldı. Testin başlangıcındaki koşu hızı 8.5 $\mathrm{km} / \mathrm{saattir}$. Sporculara, her bir sinyal aralığı dakikada $0.5 \mathrm{~km} / \mathrm{s}$ artan özel shuttle run sinyalleri ile birlikte $20 \mathrm{~m}$ çizgisine ulaşmak zorunda oldukları bildirildi. Sinyal verildiğinde 20 m'yi belirleyen çizgilerin $1 \mathrm{~m}$ önündeki iç çizgilere iki kez üst üste ulaşamayan sporcu için test sonlandırıldı (Leger ve Lambert, 1982). Sporcuların aerobik güç seviyeleri, $V O_{2 \operatorname{Max}}=3,46 x$ (level, shuttle) $+12,2$ eşitliği kullanılarak tespit edildi (Ramsbottom, Brewer ve Williams, 1988).

\section{İstatistiksel Analiz}

Elde edilen verilerin istatistiksel analizlerinin yapılmasında SPSS 25.0 istatistik programı kullanıldı. Öncelikle tüm verilerin normal dağılım gösterip göstermediği Shapiro-Wilk normallik testi ile kontrol edildi. Grupların genel özelliklerini tespit etmek amaciyla tanımlayıc1 istatistikler (ortalama, standart sapma, minimum, maksimum değerler) hesaplandı. Sporcuların motorik test sonuçları ile somatotip yapıları arasındaki ilişkilerin tespit edilebilmesi için Sperman Korelasyon Katsayısı kullanıldı.

\section{BULGULAR}

Araştırmanın bu bölümünde istatistiksel analizler neticesinde elde edilen verilere ilişkin bulgu ve yorumlara yer verildi.

Tablo 1. Sporcuların fiziksel ve demografik özelliklerine ait bulgular

\begin{tabular}{lllll}
\hline $\mathbf{n = 1 9}$ & $\mathbf{X}$ & Sd & Min. & Max. \\
\hline Yaş (yıl) & 12.16 & 0.69 & 11 & 13 \\
\hline Boy Uzunluğu $(\mathrm{cm})$ & 151.71 & 7.03 & 136 & 162 \\
\hline Vücut Ağırlığı $(\mathrm{kg})$ & 46.19 & 10.54 & 31.5 & 64.3 \\
\hline Vki $\left(\mathrm{kg} / \mathrm{m}^{2}\right)$ & 19.98 & 3.79 & 14.48 & 26.1 \\
\hline VYY $(\%)$ & 14,37 & 6,11 & 6,90 & 24 \\
\hline Antrenman yaşı (ay) & 6.68 & 4.24 & 4 & 24 \\
\hline X: arimetil ortalam
\end{tabular}

X: aritmetik ortalama; Sd.: standart sapma; Min.: minimum; Max.: maksimum; Vki: vücut kitle indeksi; VYY: vücut yağ yüzdesi 
Yapılan istatistiksel değerlendirmede; sporcuların yaş, boy uzunluğu, vücut ağırlı̆̆ı, vücut kitle indeksi, vücut yağ yüzdesi ve antrenman yaşı verilerine ait aritmetik ortalama, standart sapma, minimum ve maksimum değerleri tespit edildi (Tablo 1).

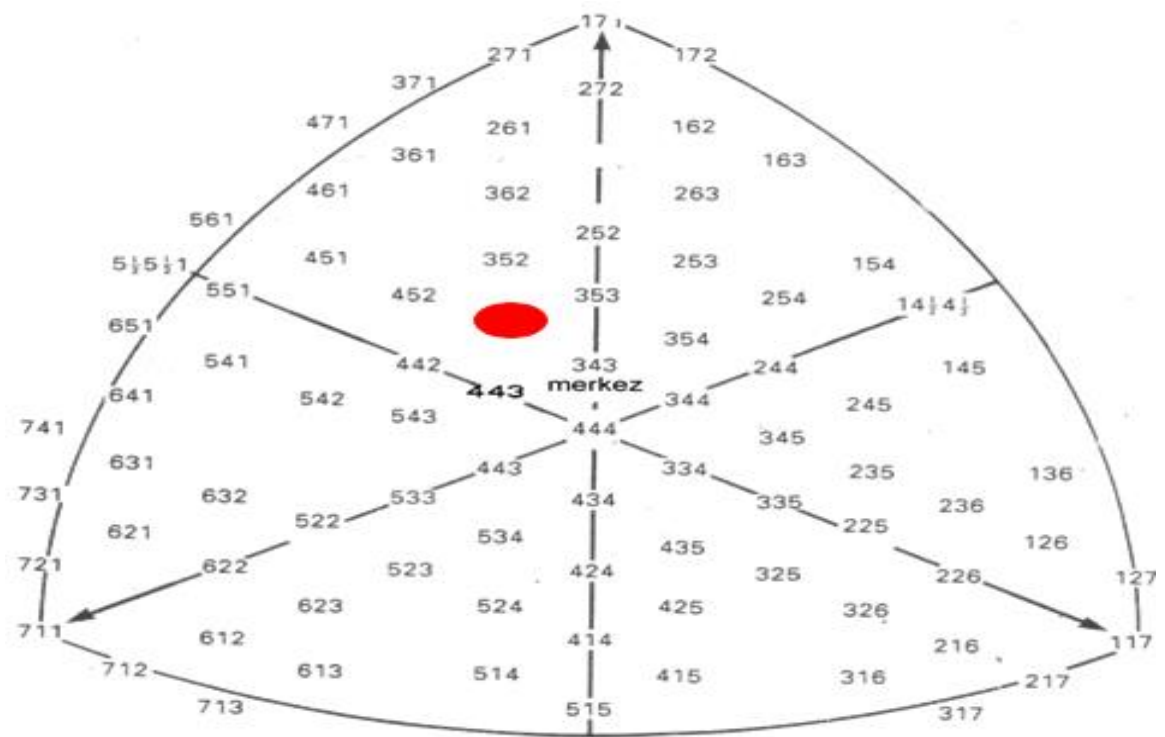

Şekil 1. Sporcuların ortalama somatotip değerleri

Yapılan istatistiksel değerlendirmede; sporcuların ortalama somatotip değerlerinin endomorfik mezomorf (4-5-3) olduğu tespit edildi (Şekil 1).

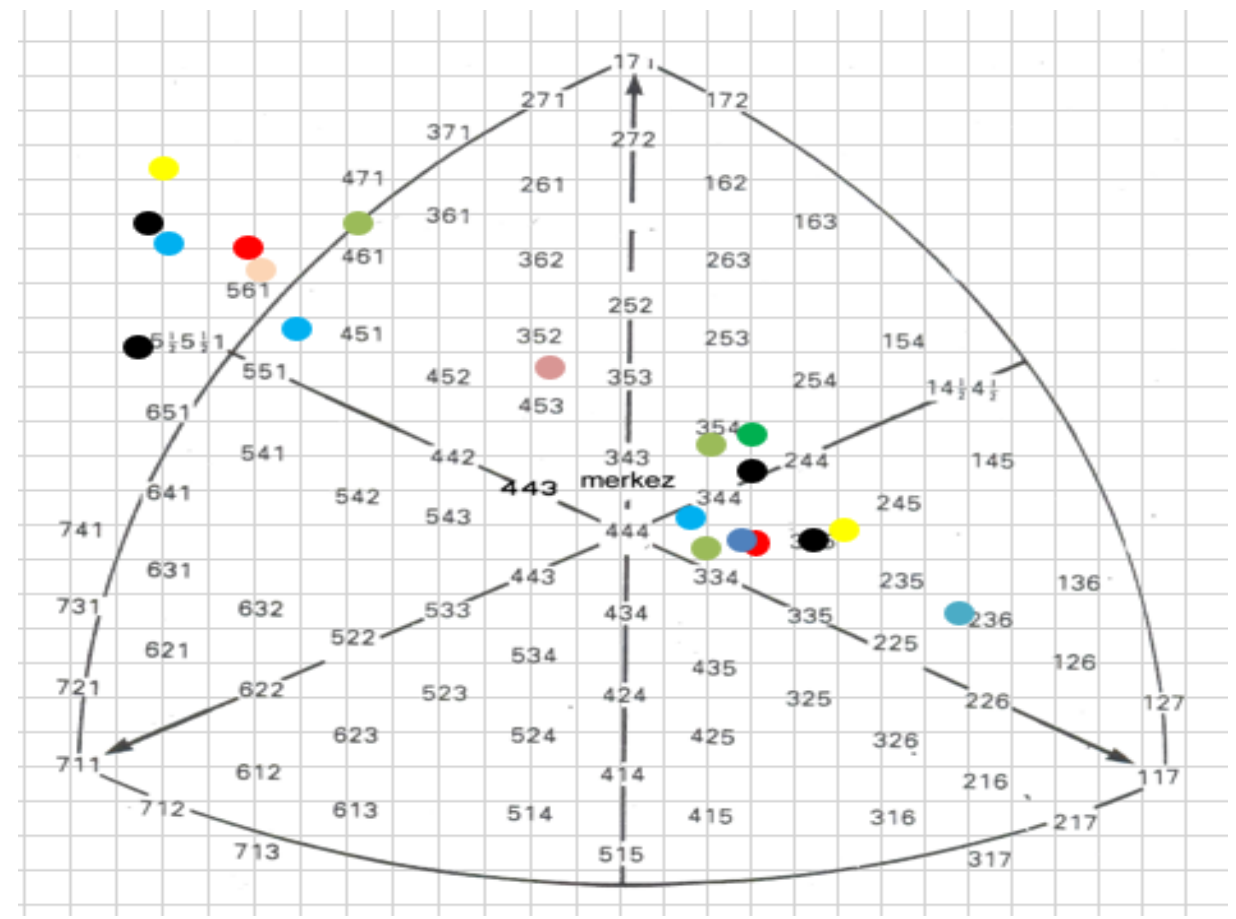

Şekil 2. Tüm sporcuların somatotip dăğlımları 
Yapılan istatistiksel değerlendirmede, araştırmamıza katılan sporcuların $(n=19)$ somatotip değerleri tespit edildi ve somatokart üzerinde gösterildi (Şekil 2).

Tablo 2. Sporcularının motorik test sonuçları ile somatotip yapıları arasındaki korelasyon ve tanımlayıcı istatistik değerleri

\begin{tabular}{|c|c|c|c|c|c|c|c|c|}
\hline \multirow[t]{2}{*}{$n=19$} & \multicolumn{4}{|c|}{$\begin{array}{c}\text { Tanımlayıcı İstatistik } \\
\text { Değerleri }\end{array}$} & \multirow{2}{*}{$\begin{array}{c}\text { Shapiro- } \\
\text { Wilk }\end{array}$} & \multicolumn{3}{|c|}{$\begin{array}{c}\text { Korelasyon Testi } \\
\text { Sonuçları }\end{array}$} \\
\hline & $\mathbf{X}$ & Sd & Min. & Max. & & Endo. & Mezo. & Ekto. \\
\hline Endomorf & 3.87 & 1.54 & 1.8 & 6.2 & 0,025 & & & \\
\hline Mezomorf & 5.15 & 1.8 & 2.4 & 8.3 & 0,178 & $0^{0.888}{ }^{* * *}$ & & \\
\hline Ektomorf & 2.81 & 1.79 & 0.3 & 5.6 & 0,017 & $-0.853^{* *}$ & $-0.901^{* *}$ & \\
\hline 20 m. Sürat (sn.) & 3.88 & 0.27 & 3.5 & 4.62 & 0,192 & $0.629^{* * *}$ & $0.506 *$ & $-0.473^{*}$ \\
\hline $\begin{array}{l}\text { İllinois Çeviklik } \\
\text { (sn.) }\end{array}$ & 19.29 & 1.41 & 17.32 & 22.67 & 0,109 & $0.664^{* *}$ & $0.664^{* *}$ & $-0.524^{* *}$ \\
\hline Dikey Sıçrama (cm) & 26.08 & 11.24 & 12 & 68 & 0,000 & -0.402 & -0.261 & 0.157 \\
\hline $\begin{array}{l}\text { Anaerobik Güç- } \\
\text { Lewis (kgm/sn) }\end{array}$ & 50,60 & 11,22 & 30,74 & 71,62 & 0,693 & $0,486 *$ & $0,648 * *$ & $-0,593 * *$ \\
\hline $\begin{array}{l}\text { Anaerobik Güç- } \\
\text { Lewis (watt) }\end{array}$ & 472.09 & 156.09 & 14.8 & 702.6 & 0,079 & 0.343 & 0.216 & $-0.471 *$ \\
\hline $\begin{array}{l}\text { Flamingo Denge } \\
\text { (düşme sayısı) }\end{array}$ & 9.37 & 3.89 & 4 & 19 & 0,195 & 0.323 & 0.226 & -0.161 \\
\hline Mekik (adet) & 17.63 & 5.75 & 1 & 25 & 0,032 & $-0.708^{* * *}$ & $-0.670^{* * *}$ & $0.565^{* *}$ \\
\hline Şınav (adet) & 10.05 & 7.07 & 0 & 23 & 0,299 & -0.379 & -0.394 & 0.177 \\
\hline $\begin{array}{l}\text { Durarak uzun } \\
\text { atlama }(\mathrm{cm})\end{array}$ & 151.05 & 18.37 & 124 & 186 & 0,405 & $-0.662^{* * *}$ & $-0.527^{*}$ & $0.521^{*}$ \\
\hline $\begin{array}{l}\text { Otur Eriş Esneklik } \\
(\mathrm{cm})\end{array}$ & 2.32 & 5.63 & -10 & 10 & 0,088 & -0.311 & -0.164 & 0.049 \\
\hline Shuttle Run & & & & & & & & \\
\hline $\begin{array}{l}\text { Dayanıklılık } \\
\text { (ml/kg/min.) }\end{array}$ & 28.17 & 5.91 & 20 & 38.2 & 0,103 & $-0.587^{* *}$ & $-0.595^{*}$ & $0.473^{*}$ \\
\hline
\end{tabular}

X: aritmetik ortalama; Sd.: standart sapma; Min.: minimum; Max.: maksimum; ${ }^{*} \mathrm{p}<0.05 ; * * \mathrm{p}<0.01$

Yapılan istatistiksel değerlendirmede; sporcuların ölçülen tüm parametrelerine ait aritmetik ortalama, standart sapma, minimum ve maksimum değerleri ve motorik test ölçüm sonuçları ile somatotip yapıları arasındaki ilişkilere ait değerler tespit edildi (Tablo 2).

\section{TARTIŞMA}

Yapılan çalışmalar, sporcuların vücut yapılarının ilgili spor dalına uygun olmasının performansı artırıcı bir etkiye sahip olduğunu göstermektedir (Ölmez ark., 2017; Yüksek ark., 2017).

Yapılan incelemede, çalışmamıza katılan sporcuların ortalama boy uzunluklarının $151.71 \pm$ $7.03 \mathrm{~cm}$, vücut ağırlıklarının $46.19 \pm 10.54 \mathrm{~kg}$, vücut kitle indeksi değerinin $19.9 \pm 3.8$ $\mathrm{kg} / \mathrm{m}^{2}$ ve vücut yağ yüzdelerinin $14,37 \pm 6,11$ (\%) olduğu tespit edildi. Sporcuların vücut kitle indeksi (Fritzsche ve Raschka, 2008; Göksu, Yüksek ve Ölmez, 2018; Kazemi ark., 
2006; Revan ark., 2017) ve vücut yă̆ yüzdesi (Özen ve Nur, 2017) değerleri literatürle benzer niteliktedir.

Çalışmada, sporcuların endomorfik mezomorf (4-5-3) bir yapıya sahip olduğu tespit edildi. Revan ve ark., (2017), 45'i Türk (27 erkek, 18 kadın), 48'i yabancı (35 erkek, 13 kadın) 93 milli taekwondo sporcusu ile yaptıkları araştırmada, yabancı erkek taekwondocuların somatotip yapılarının mezomorfik ektomorf (1.67-3.39-4.31), Türk erkek taekwondocuların somatotip yapılarının ise, mezomorf- ektomorf (1.73-3.84-3.81) olduğunu rapor etmişlerdir. Farklı bir çalışmada Fritzsche ve Raschka (2008), iki farklı performans seviyesine sahip 50 taekwondo sporcusu ile yaptıkları çalışmada, elit taekwondocuların ektomorfik mezomorf (3.0-4.7-3.8), rekreasyonel amaçlı taekwondo ile ilgilenen bireylerin ise, endomorfik mezomorf (3.6-5.4-2.9) bir yapıya sahip olduğunu rapor etmişlerdir. Yapılan çalışmada elit ve sub-elit düzeydeki sporcuların farklı somatotip puanlarına sahip olduğu gözükmektedir. Benzer şekilde Ghorbanzadeh ark., (2011), elit ve sub-elit taekwondocuların vücut yapılarını inceledikleri çalışmada, elit (2.58-2.63-3.51) ve sub-elit (1.96-3.59-3.75) sporcuların vücut yapılarının mezomorfik ektomorf olduğunu, fakat elit grubun mezomorf değerlerinin daha yüksek, ektomorf değerlerinin daha düşün puanda olduğunu tespit etmişlerdir. Literatürde, elit taekwondocuların somatotip yapılarının ektomorfik (Ghorbanzadeh ark., 2011), ektomorfik-mezomorf (Kazemi ark., 2006; León, Viramontes ve Veitía, 2009; Taaffe ve Pieter, 1990) ya da mezomorf-ektomorf (Noh, Kim ve Kim, 2013; Pieter, 1991; Pieter, 2008) değerleri arasında olduğu, fakat rekreasyonel anlamda taekwondo ile ilgilenen bireylerin, endomorf ve mezomorf değerlerinin daha yüksek (Chan, Pieter ve Moloney, 2003; Čular ark., 2013; Fritzsche ve Raschka, 2008) olduğu tespit edildi. Çalışmamıza katılan sporcuların yaş grubu ve antrenman seviyeleri göz önünde bulundurulursa, elit sporculardan farklı bir vücut tipine ya da performans seviyesine sahip olmaları beklenebilir. Sub-elit düzeyde ya da rekreasyonel amaçlı taekwondo yapan sporcuların endomorf ve mezomorf değerlerinin ektomorf değerlerinde daha yüksek olması, çalışmamızı destekler niteliktedir.

Sporcuların endomorf değerleri ile mezomorf değerleri arasında pozitif yönde ve yüksek düzeyde, ektomorf değerleri ile endomorf ve mezomorf değerleri arasında ise ters yönde ve yüksek düzeyde anlamlı bir ilişki olduğu tespit edildi. Somatotip yapının endomorfik mezomorf olduğu bir durumda, bu ilişkilerin bulunması beklenen bir durumdur.

Somatotip yapı ile performans becerileri arasındaki ilişkiler incelendiğinde ise, sporcuların endomorf ve mezomorf değerleri ile mekik becerileri arasında negatif yönde yüksek ve orta düzeyde, çeviklik becerileri arasında pozitif yönde ve orta düzeyde, sürat becerileri arasında pozitif yönde ve orta düzeyde, durarak uzun atlama ve dayanıklılık becerileri arasında ise, negatif yönde ve orta düzeyde anlamlı bir ilişki olduğu tespit edildi (Tablo 2). Bir başka deyişle sporcuların yağlılık ve kaslılık oranı birbirine paralel bir şekilde arttıkça çeviklik, sürat, mekik, durarak uzun atlama ve dayanıklılık performanslarında azalma olmaktadır. $\mathrm{Bu}$ sonucun, sporcuların endomorf yapılarının baskın olmasından kaynaklandığı düşünülmektedir. Ayrıca sporcuların anaerobik güç $(\mathrm{kgm} / \mathrm{sn})$ performansları ile endomorf yapıları arasında pozitif yönde ve düşük düzeyde, mezomorf yapıları arasında ise, pozitif yönde ve orta düzeyde anlamlı bir ilişki olduğu tespit edildi (Tablo 2). Sporcuların mezomorf değerleri arttıkça anaerobik güç değerlerinde de artış olmaktadır. Endomorf değerleri ve anaerobik güç değerleri arasındaki düşük düzeyli ve anlamlı ilişkinin ise, sporcuların 
mezomorf ve endomorf yapıları arasındaki yüksek düzeyli ve pozitif yönlü ilişkiden kaynaklandığı düşünülmektedir. Fakat sporcuların ektomorf değerleri ile mekik ve durarak uzun atlama becerileri arasında pozitif yönde ve orta düzeyde, çeviklik becerileri arasında ise negatif yönde ve orta düzeyde, sürat ve anaerobik güç becerileri arasında negatif yönde ve düşük-orta düzeyde, dayanıklılık becerileri arasında ise pozitif yönde ve düşük düzeyde anlamlı bir ilişki olduğu tespit edildi (Tablo 2). Sporcuların zayıflık oranı artıkça sürat, çeviklik, durarak uzun atlama ve dayanıklılık performanslarında artış, anaerobik güç performanslarında ise düşüş olmaktadır. Taekwondonun sıklet sporu oluşu ve performans talebi, sporcuların ektomorf ve mezomorf değerlerinin endomorf değerlerinden daha yüksek olmasını gerektirmektedir. Araştırma sonuçlarından da anlaşıldığı gibi, endomorf değerlerin yüksek düzeyde olması, performansı kısıtlayıcı bir etki oluşturmaktadır.

Bridge ark., (2014) yapmış oldukları araştırmalarında, taekwondo sporcularının yağsız bir profilde ve yüksek anaerobik güç, dayanıklılık ve esneklik becerilerine sahip olmaları gerektiğini ifade etmişlerdir. Burdukiewicz ark., (2018) taekwondo ve diğer mücadele sporcularının morfolojik yapılarının incelenmesi amacı ile yapmış oldukları çalışmalarında $(n=206)$, çeviklik performansının baskın olduğu taekwondo gibi mücadele sporlarında mezomorf ve ektomorf değerlerinin baskın olması gerektiğini rapor etmişlerdir. Marta ark., (2013) 125 çocuk ile yaptıkları çalışmada, endomorf değerlerinin yüksek oluşunun dikey sıçrama performansını olumsuz etkilediğini, artan ektomorf ve mezomorf değerlerinin ise, sürat ve dayanıklılık performansını olumlu yönde etkilediğini bildirmişlerdir. Benzer şekilde Ayan, Kaya ve Erol (2011), 171 çocuk ile yaptıkları çalışmada, çocuklarda dikey sıçrama, durarak uzun atlama ve sürat performansının, yüksek endomorf değerinden olumsuz yönde etkilendiğini fakat yüksek ektomorf değerinden olumlu yönde etkilendiğini rapor etmişlerdir. Marinho ark., (2016) ise karma dövüş sanatları ile ilgilenen 8 sporcu ile yaptıkları çalışmada, sporcuların kuvvet ve kuvvette devamlılık performanslarının ektomorfik yapılarından olumlu yönde etkilendiğini fakat endomorfik yapılarından olumsuz yönde etkilendiğini bildirmişlerdir. Seo ark., (2015) 34 taekwondo sporcusu ile yaptıkları araştırma sonunda, taekwondo antrenmanlarının vücut kompozisyonunu düzenleyip ve anaerobik güç, sürat, dayanıklılık ve esneklik parametrelerinde gelişim sağladığını bildirmişlerdir. Arabacı ark., (2011) 17 elit taekwondo sporcusu ile yaptıkları araştırmada, taekwondocuların bacak yağ yüzdeleri ve yă̆ miktarlarının az olmasının alt ekstremite reaksiyon zamanlarını olumlu yönde etkilediğini, ayrıca total vücut yağ yüzdelerinin düşük olmasının sportif performanslarını olumlu yönde etkileyebileceğini rapor etmişlerdir. İncelenen araştırmalara dayanarak, taekwondo sporcularının endomorf değerlerinin mezomorf ve ektomorf değerlerinden daha düşük olmasının, sportif performanslarının gelişimi için avantaj sağlayabileceği söylenebilir. Artan vücut yağı ve azalan kas oranı, sportif performans için gerekli olan temel motorik özelliklerin yüksek düzeyde sergilenebilmesini engellemektedir. Tam aksine azalan vücut yağı ve artan kaslılık oranı, sportif performans için gerekli olan motorik özelliklerin icrasını kolaylaştırmaktadır. Bu anlamda incelenen araştırmalar, çalışmamızı destekler niteliktedir.

\section{SONUÇ}

Kuvvet, sürat, dayanıklılık, çeviklik, esneklik ve denge parametreleri çoğu spor dalının bünyesinde bulundurduğu ortak ve temel motorik özelliklerdir. $\mathrm{Bu}$ özelliklerin genel ve branşa özgü olarak mükemmelleştirilebilmesi, sporculara fiziksel uygunluğun sağlanabilmesi ve spora özgü performansın geliştirilebilmesi adına katkı sağlar. Sonuç olarak, 11-13 yaş erkek taekwondocularda, taekwondonun talep ettiği fakat doğrudan taekwondoya özgü olmayan temel motorik özelliklerin maksimum seviyede sergilenebilmesi için uygun vücut 
tipinin ektomorf ya da ektomorfik mezomorf olduğu anlaşılmaktadır. Elit seviye sporcuların vücut tiplerinin ektomorf ya da ektomorfik mezomorf oluşu ise, taekwondoya özel teknik becerilerin, müsabaka bileşenlerinin ya da taekwondo bünyesindeki diğer unsurların, temel motorik özellikler ile aynı vücut tipini talep ettiğini göstermektedir. Çalışmamızda sporcuların ektomorf değerleri arttıkça sürat ve çeviklik zamanları kısalmakta; mekik, durarak uzun atlama ve dayanıklılık değerleri artmakta ve sporculara avantaj sağlamaktadır. Ayrıca sporcuların endomorf değerleri arttıkça sürat ve çabukluk zamanları artmakta; mekik, durarak uzun atlama ve dayanıklılık değerleri azalmakta ve sporculara dezavantaj sağlamaktadır. Dolayısıyla ergenlik öncesi taekwondo sporcularının seçiminde ya da mevcut sporcular için hedef performansın sağlanabilmesi adına gereken vücut tipinin belirlenmesinde, ektomorfik bir vücut tipi planlanmalıdır. Araştırmamıza ait sonuçların, ilgili bilim insanlarına, beden eğitimi öğretmenlerine, antrenörlere, yetenek taraması projelerinde görevli uzmanlara ve yürütücülere, çocuklara ve ebeveynlerine katkı sağlayacağı beklenmektedir.

\section{KAYNAKLAR}

Arabacı, R., Çankaya, C., Çatıkkaş, F., \& Şahin, S. (2011). Assessment body composition and leg reaction time of elite taekwondo athletes. Sport Sciences, 6(2), 139-147.

Aragón, L. (2000). Evaluation of four vertical jump tests: methodology, reliability, validity, and accuracy. Measurement in Physical Education and Exercise Science, 4(4), 215-28.

Ayan, V., Kaya, M., \& Erol, E. (2011). Erkek çocuklarının futbol branşı için somatotip ve performans özelliklerinin incelenmesi. Journal of Physical Education Sports Science, 5(3), 266-273.

Bayios, I. A., Bergeles, N. K., Apostolidis, N. G., Noutsos, K. S., \& Koskolou, M. D. (2006). Anthropometric, body composition and somatotype differences of Greek elite female basketball, volleyball and handball players. Journal of Sports Medicine and Physical Fitness, 46(2), 271-280.

Bridge, C., Ferreira, J., Chaabène, H., Pieter, W., \& Franchini, E. (2014). Physical and physiological profiles of taekwondo athletes. Sports Medicine, 44(6), 713-733.

Burdukiewicz, A., Pietraszewska, J., Stachoń, A., \& Andrzejewska, J. (2018). Anthropometric profile of combata athletes via multivariate analysis. The Journal of Sports Medicine and Physical Fitness, $58(11), 1657-1665$.

Chan, K., Pieter, W., \& Moloney, K. (2003). Kinathropometric profile of recreational taekwondo athletes. Biology of Sport, 20(3), 175-179.

Čular, D., Milić, M., Bilić-Pavlinović, A., Katić, R., Kuvačić, G., \& Vrdoljak, J. (2013). Somatotype of young taekwondo competitors. Research in Physical Education Sport and Health, 2(2), 27-33.

Dardouri, W., Gharbi, Z., Selmi, M., Sassi, R., Moalla, W., Chamari, K., \& al., e. (2014). Reliability and validity of a new maximal anaerobic shuttle running test. International Journal of Sports Medicine, 35(4), 310-315.

Fox, E. L., \& Mathews, D. K. (1974). Interval Training: Conditioning for Sports and General Fitness. Philadelphia: Saunders.

Fritzsche, J., \& Raschka, C. (2008). Body composition and the somatotype of German top taekwondo practitioners. Papers on Anthropology, 17(1), 58-71. 
Ghorbanzadeh, B., Müniroğlu, S., Akalan, C., Khodadadi, M., Kirazcı, S., \& Şahin, M. (2011). Determination of taekwondo national team selection criterions by measuring physical and physiological parameters. Annals of Biological Research, 2(6), 184-197.

Göksu, Ö., Yüksek, S., \& Ölmez, C. (2018). The investigation of the motor skills of" u" categories soccer players who have recreative involvement in other sports. Journal of Education and Training Studies, $6(2), 10-17$.

James, R., Allen, W., James, G., \& Dale, P. (2005). Measurement and Evaluation in Human Performance. USA: Human Kinetics.

Katić, R., Blažević, S., Krstulović, S., \& Mulić, R. (2005). Morphological structures of elite karateka and their impact on technical and fighting efficiency. Collegium Antropologicum, 29(1), 79-84.

Kaynar, Ö. (2018). Investigation of talent selection methods in different sports branches. Journal of Education and Training Studies, 6(12a), 44-48.

Kazemi, M., Waalen, J., Morgan, C., \& White, A. (2006). A profile of olympic taekwondo competitors. Journal of Sports Science Medicine, 5(CSSI1), 114-121.

Kent, M., \& Kent, D. M. (2006). The Oxford dictionary of sports science and medicine (Vol. 56). New York: Oxford University Press.

Kim, Y. H., \& Khil, J. H. (2010). Effects of 12 week's taekwondo combined exercise program on body composition and physical fitness in middle aged obese women. The Official Journal of the Korean Academy of Kinesiology, 12(2), 67-77.

Leger, L., \& Lambert, J. (1982). A maximal multistage $20 \mathrm{~m}$ shuttle run test to predict Vo2max. European Journal of Applied Physiology and Occupational Physiology, 49(1), 1-12.

León, H., Viramontes, J., \& Veitía, W. (2009). Anthropological estimation of the body shape of cuban elite combat athletes from olympic sports. Antropo, 19(3), 23-32.

Marangoz, I. (2018). The determination of the relationship between somatotypes and speed of sub-elite athletes. Asian Journal of Education and Training, 4(3), 220-223.

Marković, G., Mišigoj-Duraković, M., \& Trninić, S. (2005). Fitness profile of elite Croatian female taekwondo athletes. Collegium Antropologicum, 29(1), 93-99.

Marinho, B., Follmer, B., Esteves, J., \& Andreato, L. (2016). Body composition, somatotype and physical fitness of mixed martial arts athletes. Sport Sciences for Health, 12(2), 157-165.

Marta, C., Marinho, D., Barbosa, T., Carneiro, A., Izquierdo, M., \& Marques, M. (2013). Effects of body fat and dominant somatotype on explosive strength and aerobic capacity trainability in prepubescent children. The Journal of Strength Conditioning Research, 27(12), 3233-3244.

Massidda, M., Toselli, S., Brasili, P., \& M Calo, C. (2013). Somatotype of elite Italian gymnasts. Collegium Antropologicum, 37(3), 853-857.

Maulder, P., \& Cronin, J. (2005). Horizontal and vertical jump assessment: reliability, symmetry, discriminative and predictive ability. Physical Therapy in Sport, 6(2), 74-82.

Noh, J., Kim, J., \& Kim, J. (2013). Somatotype analysis of elite taekwondo athletes compared to non-athletes for sports health sciences. Toxicology and Environmental Health Sciences, 5(4), 189-196.

Norton, K., \& Olds, T. (2004). Anthropometrica, a text book of body measurement for sports and health courses. Australia: Unsw Press.

Ölmez, C., Yüksek, S., Üçüncü, M., \& Ayan, V. (2017). 8-12 yaş çocuklarda bazı antropometrik özellikler ile 50 metre serbest stil yüzme performansı arasındaki ilişkinin incelenmesi. Türkiye Klinikleri Spor Bilimleri Dergisi, 9(3), 95-100. 
Özen, A., \& Nur, F. (2017). 17-21 yaş arası IBBSSK bünyesinde bulunan elit ve elit olmayan taekwondoculartn vücut yăg oranlarının karşılaş̧trılması (Yüksek Lisans Tezi, İstanbul Gelişim Üniversitesi Sağlık Bilimleri Enstitüsü).

Pieter, W. (1991). Performance characteristics of elite taekwondo athletes. Korean Journal of Sport Science, $3(1), 94-117$.

Pieter, W. (2008). Body build of elite taekwondo athletes. Acta Kinesiologiae Universitatis Tartuensis, 13(8), 99-106.

Ramsbottom, R., Brewer, J., \& Williams, C. (1988). Progressive shuttle run test to estimate maximal oxygen uptake. British Journal of Sports Medicine, 22(4), 141-44.

Reilly, T., \& Williams, M. (2003). Science and soccer. New York: Routledge.

Revan, S., Arıkan, Ş., Şahin, M., \& Balcı, Ş. (2017). Comparison of the body composition and somatotype of Turkish and foreign country national team taekwondo athletes. European Journal of Physical Education and Sport Science, 3(12), 287-295.

Seo, W., Jung, C., Song, K., \& Kim, B. (2015). Effect of 8 weeks of pre-season training on body composition, physical fitness, anaerobic capacity, and isokinetic muscle strength in male and female collegiate taekwondo athletes. Journal of Exercise Rehabilitation, 11(2), 101-107.

Sterkowicz-Przybycień, K., Sterkowicz, S., \& Żarów, R. (2011). Somatotype, body composition and proportionality in polish top greco-roman wrestlers. Journal of Human Kinetics, 28, 141-154.

Taaffe, D., \& Pieter, W. (1990). Physical and physiological characteristics of elite taekwondo athletes. D. Taaffe, \& W. Pieter içinde, Common wealth and international proceedings (s. 80-88). New Zealand: Auckland.

Tamer, K. (2000). Sporda fiziksel performansın ölçülmesi ve değerlendirilmesi. Ankara: Bağırgan Yayınevi.

Tel, M. (2008). Bir spor dalı olarak taekwondo. Sport Sciences, 3(4), 194-202.

Tsigilis, N., Douda, H., \& Tokmakidis, S. (2002). Test-retest reliability of the eurofit test battery administered to university students. Perceptual and Motor Skills, 95(3), 1295-300.

Wood, R. (2017). Speed or sprint testing. Topend Sports: http://www.topendsports.com/testing/tests/sprint.htm adresinden alınd.

Wood, R. (2018). Flamingo Balance Test. Topend Sports: http://www.topendsports.com/testing/tests/balanceflamingo.htm adresinden alındı.

Wood, R. (2018). Push-Up Test / Press Up Test. Topend Sports: https://www.topendsports.com/testing/tests/push-up.htm adresinden alındı.

Wood, R. (2018). V-Sit Reach Flexibility Test. Topend Sports: http://www.topendsports.com/testing/tests/vsit.htm adresinden alındi.

World Medical Association. (2019). Declaration of Helsinki-Ethical Principles for Medical Research Involving Human Subjects. World Medical Association: https://www.wma.net/policies-post/wma-declaration-ofhelsinki-ethical-principles-for- adresinden alındı.

Yüksek, S., Akpınar, E., Ayan, V., \& Ölmez, C. (2017). 14-16 yaş yüzücülerde antropometrik özellikler ile 50 metre sırtüstü stil yüzme performansları arasındaki ilişkinin incelenmesi. İstanbul Üniversitesi Spor Bilimleri Dergisi., 7(2), 13-26. 